\title{
"It's Not like This Back Home" Conversations and Conversation Analysis as a Tool to Consider the Family Medicine Consultation in India
}

\author{
Kay Mohanna ${ }^{1 *}$ \\ ${ }^{1}$ Professor of Values Based Healthcare Education, University of Worcester, Henwick Grove, Worcester WR2 6AJ, United Kingdom
}

\begin{abstract}
Introduction: This paper describes some of the features of family medicine consultations in one clinic in India. In the United Kingdom (UK) there is a significant difference in the success rate in the Royal College of General Practice Postgraduate Licensing Assessment (MRCGP) between those doctors who graduated MBBS from overseas but who trained and work in the UK, and those who graduated in the UK. The reasons for this are not known, but are likely to be multifactorial. India is the country of origin of one of the largest groups of UK International Medical Graduates (IMGs) and some doctors from India feel that their difficulty in passing this exam is in part due to family medicine being performed differently in India.

Methods: The reported experiences of family medicine trained doctors in India about contextual aspects of practice are explored through a thematic analysis of focus group and interviews. A conversation analysis of work done by talk-in-interaction in video recordings of actual family medicine consultations in India is also presented.

Results and Discussion: The impact of family medicine training, or the lack of it, and Indian structural and societal norms in the practice of family medicine are considered. The Clinical Skills Assessment element of MRCGP (CSA) heavily emphasises talk as used in all three assessment domains - data gathering, clinical management and interpersonal skills. The phrase 'interactional fluidity' is coined for the marker of competence with talk that RCGP examiners seek. This has implications in a high-stakes, yet simulated, assessment for those consulting in a second language. Using a model that differentiates between 'core business work talk', 'workrelated talk' and 'small talk', the talk from video-recorded real-life consultations in India will be analysed. The risk of UK examiners mistaking unfamiliar patterns of talk for lack of medical competence is discussed.
\end{abstract}

Conclusion: The differential attainment of IMGs has been described for some time and this paper aims to move the discussion on to potential training interventions in response.

Keywords: Family medicine, India, MRCGP, thematic analysis, conversation analysis, small talk.

\section{BACKGROUND}

This project started with a concern for fairness in the Clinical Skills Assessment (CSA) component of the licensing exam for United Kingdom (UK) general practice as organised by the Royal College of General Practitioners (MRCGP). In common with assessments in other UK medical specialities and across other postgraduate settings and professions, International Medical Graduates (IMGs) have a much higher failure rate in the CSA than UK graduates (GMC 2019). The latest annual overall figures for the CSA are shown in Table 1 [1].

India is the country of origin of one of the largest groups of overseas candidates in the UK, forming around $20 \%$ of those from outside of the UK/EEA. This paper presents a thematic analysis of interview and focus group data from doctors working in one clinic in India with conversation analysis of video-recorded consultations to look at the features of the family medicine consultation.

*Corresponding Author: Kay Mohanna, Professor of Values Based Healthcare Education, University of Worcester, Henwick Grove, Worcester WR26AJ, United Kingdom;Email:k.mohanna@worc.ac.uk

Received: October 12, 2019; Revised: December 27, 2019; Accepted: December 31, 2019 DOI: https://doi.org/10.37184/lnjpc.2707-3521.1.9
Table. 1: Outcomes for those candidates sitting CSA for the first attempt, August 2017 -July 2018. (Excludes some candidates whose gender was not declared) [2].

\begin{tabular}{c|c|c|c}
\hline \multirow{2}{*}{ PMQ } & $\begin{array}{c}\text { Candidate } \\
\text { Sex }\end{array}$ & $\begin{array}{c}\text { N } \\
\text { Candidates }\end{array}$ & Result \\
\cline { 3 - 4 } & Female & 283 & $49.5 \%$ \\
\hline \multirow{3}{*}{ IMG } & Male & 168 & $35.1 \%$ \\
\cline { 2 - 4 } & Total & 451 & $44.1 \%$ \\
\hline \multirow{3}{*}{ UKG } & Female & 1808 & $93.9 \%$ \\
\cline { 2 - 4 } & Male & 718 & $86.5 \%$ \\
\cline { 2 - 4 } & Total & 2126 & $91.4 \%$ \\
\hline
\end{tabular}

The CSA is an assessment of consulting with a strong emphasis on interpersonal skills, and conversation analysis allows a focus on the fine detail of the form of consulting that doctors and patients use to create and sustain successful doctor-patient-relationships; relationships that in themselves then become part of the wider environment within which those consultations take place. A thematic analysis of the focus group and interview data was needed to contextualise those findings and identify patterned meaning in the descriptions of features of the context from the perspective of the doctors in the clinic. 


\section{CONTEXT OF THE STUDY}

Problematizing Assessment in UK General Practice:

The CSA is a simulated surgery where the candidates are 'consulted' by role-player 'patients'. It can only be attempted by those in general practice postgraduate training posts within the UK. In 2017-18, more than one in five of all CSA candidates had obtained their undergraduate medical degree outside the UK. For first-time candidates the pass rate was $90.8 \%$ for UK graduates, and $44.3 \%$ for non-UK graduates. Of those from outside Europe, South Asian candidates made up $56 \%$ of the international graduates. For Indian graduates, the pass mark was $32.4 \%$ [2]. Table 2 shows the pass rates for all candidates taking it for the first time.

Table. 2: First-time pass rates for those candidates in 2017-18 who graduated outside the UK [2].

\begin{tabular}{l|c|c|c}
\hline $\begin{array}{c}\text { Country of } \\
\text { Primary Medical } \\
\text { Qualification }\end{array}$ & $\begin{array}{c}\mathbf{N} \\
\text { Candidates }\end{array}$ & $\begin{array}{c}\mathbf{N} \\
\text { Passing } \\
\text { Candidates }\end{array}$ & Pass Rate \\
\hline Bangladesh & 12 & 7 & $58.3 \%$ \\
\hline Czech Republic & 22 & 12 & $54.5 \%$ \\
\hline India & 68 & 22 & $32.4 \%$ \\
\hline Iraq & 18 & 8 & $44.4 \%$ \\
\hline Ireland & 19 & 17 & $89.5 \%$ \\
\hline Nepal & 12 & 5 & $41.7 \%$ \\
\hline Nigeria & 78 & 31 & $39.7 \%$ \\
\hline Pakistan & 100 & 45 & $45.0 \%$ \\
\hline Poland & 13 & 8 & $61.5 \%$ \\
\hline South Africa & 5 & 5 & $100.0 \%$ \\
\hline All other countries & 132 & 52 & $34.4 \%$ \\
\hline Total & $\mathbf{4 7 9}$ & $\mathbf{2 1 2}$ & $\mathbf{4 4 . 3 \%}$ \\
\hline
\end{tabular}

The reasons for this differential attainment are multifactorial. The RCGP privileges a model of consulting that is largely patient-centred, and has developed the CSA assessment criteria on that basis. But this model has largely been derived, and tested, in western settings. Early in the research, one of the UK trainees who had graduated in India said:

"It's different here, the two countries are very different, the ways doctors are seen is very different. If I do the same consultation [like one for UK practice] back home in India honestly no patients would come back to me after if I ask them what do they think is going on. If I say 'what do you think is wrong, what do you think might help?' They'll think 'this doctor she doesn't know anything, I won't come back'. Whereas it's like 'you are the one who has gone through training you should know what is wrong with me'. It's more doctor-centric; we have a duty to tell them what to do".

In addition, although the specialty of family medicine has been recognised in India since 1983, there is virtually no inclusion in the undergraduate curriculum [3]. Doctors leaving medical school may have had no exposure to the academic and scholarly discipline of generalism and no practical experience of it in action. For every medical school graduate in India there are overall only
0.3 postgraduate training places for all specialties, of which nationally the family medicine places are falling from a peak of less than 200 for the whole country. We can see that those coming to the UK for postgraduate training are unlikely then to have had opportunities at undergraduate or postgraduate level to develop the same type and range of skills of generalist practice, compared to a UK graduate, whose medical school is very likely to have had considerable placements in primary care.

Increasingly, the Indian government is recognising that an emphasis on primary and community care can reduce health inequalities. For example in the Indian Government Twelfth Five Year Plan the government aspires to Universal Health Coverage and recognises that the increasing burden of non-communicable disease in particular is best addressed by increasing the capacity in primary care and that expenditures on primary healthcare should account for at least 70 per cent of all healthcare expenditure [4]. Over time, if this aspiration is achieved and the opportunities in family medicine increase, then the numbers of Indian GP trainees coming to the UK for postgraduate training might well decrease. Until that time, in order to achieve recognition of their professional status, doctors come to the UK and aspire to a British qualification, even when they plan to return home to practice.

\section{TALK-AS-WORK}

Roberts et al. [5] looked at videotaped consultations from the CSA in 2014 and showed that the exam has a specific linguistic 'fingerprint':

There are some words and phrases that are particular to the CSA, suggesting strong 'formulaic' differences from aspects of everyday spoken English [which] cluster around the social/interpersonal work of the CSA and show that it has a strong patient-centred model [5].

It seems likely that the way doctors and patients talk together will be governed by a wide range of factors which will vary from one country to another. For example Moore found that Nepalese patients expected doctors to take control of the consultation and a 'caring' relationship was more important than one in which power, or decision making, was shared [6]. Moore noted that a strong social hierarchy affected the doctor-patient relationship, which was also noted in Indonesia [7]:

"Southeast Asian culture is characterized by a hierarchical social structure. A large power distance between people of higher and lower social status is combined with a collective rather than an individual orientation. This results in less autonomy for individuals in making decisions, and for patients, strong involvement of their family in medical decisions. High value is placed on nonverbal expressions of etiquettes of politeness [7]".

The family medicine consultation is a socially constructed event which is likely to include a shifting and variable balance in the exercise of and response 
to power relationships which will be socially formed and culturally bounded, just as alluded to above and in other work [8-10]. The doctor-patient relationship sits in the context of the status of doctors in a society, is affected by the locus of knowledge and thus power within the dyadic relationship, is enacted and enabled through the social norms dictating behaviours of both actors but is also created through the interpersonal skills of each acting together. Together their actions will co-create and perpetuate what is seen as culturally appropriate and effective consulting. Examiners and candidates (and simulated patients) in the UK CSA will be affected by this.

Conversation analysis is the study of the development of meaning and context by looking at talk-in-interaction [11]. It is particularly a way of looking at how the social order, 'what things are like round here', is perpetuated through talk [11].

The underpinning theory of how conversation analysis can shed light on the development of the social order is that a conversation is mutually negotiated by the interactants, 'in-the-moment', in taken-for-granted ways that they may not even be aware of.

In one of the earliest pieces of research looking at medical work-related talk Drew and Heritage [12] identified that the three differentiating features of institutional talk as compared to 'ordinary conversation' were goal-orientation by the participants, some form of constraint as to appropriate features of the talk and the use of particular 'inferential frameworks' within the talk:

Ways of being polite, showing interest, raising concerns, arguing, all require interactants to understand the correct degree of '[attention] to the right things, at the right moments and conveying just the right degree of involvement' [13].
But what if these two people come from different countries, where politeness or respect are signalled by differing degrees of eye contact for example? If you are in an assessment situation, attempting to persuade an examiner that you are a safe and effective doctor, whilst consulting with an actor who is pretending to be a patient, you need to be able to reproduce, and make visible, the appropriate degree of smooth, un-self conscious involvement that conveys the meaning 'Good Doctor'.

In addition to performing work-related talk effectively, analysis of the CSA has shown that managing what Roberts called 'everyday social chat' is an 'important component of success in the CSA' [5]. These authors noted that successful candidates use 'conversationalising strategies' more than unsuccessful candidates, 'small markers that make the consultation more informal' (ibid p47) and that 'sustaining social relationships is a highly indicative feature of talk in the CSA' (Ibid p35). Together such small talk seem to contribute to a demonstration of what we can call 'interactional fluidity' that the examiners require.

The literature ascribes a range of functions to so called small talk. In a general practice consultation it might be doing much of the work of the interaction as it is used, among other roles, to build relationships that act as the foundation for current and future medical work. From the first rudimentary treatment on the pro-social function of such 'phatic communion' [14] to the communicative function of small talk [15] including work on politeness and ideas of 'face' [16] and rapport management [17], to the form and function of small talk in a variety of social settings [18] including at work [19] and in health-related contexts (e.g. Coupland et al. 1992, 1994) and with the understanding of the importance of small talk that 'oils the wheels' at work [19] but that it can be problematic in cross-cultural settings [20], small talk is of growing interest.

Table. 3: Themes and codes.

\begin{tabular}{|c|c|c|c|c|c|}
\hline Theme & $\begin{array}{l}\text { Medicine Reflects } \\
\text { Societal Norms }\end{array}$ & $\begin{array}{c}\text { Language is More Than } \\
\text { Just Words - but They } \\
\text { Help }\end{array}$ & $\begin{array}{c}\text { Our Education and } \\
\text { Training Does Not } \\
\text { Prepare Us For } \\
\text { Practice } \\
\end{array}$ & $\begin{array}{l}\text { Recognition of Family } \\
\text { Medicine/General } \\
\text { Practice }\end{array}$ & The Influence of Money \\
\hline Codes & $\begin{array}{l}\text { The doctor is of high } \\
\text { social status } \\
\text { The doctor is expected } \\
\text { to 'know' } \\
\text { Collectivism vs } \\
\text { individualism and } \\
\text { autonomy } \\
\text { Barriers to taking a } \\
\text { full history; sexual or } \\
\text { psychiatric }\end{array}$ & $\begin{array}{l}\text { The doctor has to } \\
\text { 'connect' with the patient } \\
\text { Medicine is mostly learnt } \\
\text { in English } \\
\text { Multiplicity of regional } \\
\text { languages } \\
\text { We don't talk about the } \\
\text { weather ('small talk') }\end{array}$ & $\begin{array}{l}\text { We don't have } \\
\text { communication skills } \\
\text { training in UG } \\
\text { (Indian doctors are very } \\
\text { adaptable) } \\
\text { There is no training } \\
\text { programme in how to be } \\
\text { a GP } \\
\text { There are few } \\
\text { opportunities for CPD }\end{array}$ & $\begin{array}{l}\text { Family medicine as a } \\
\text { career is a default option } \\
\text { Lack of employment } \\
\text { opportunities } \\
\text { Understanding of GP role } \\
\text { in community is poor } \\
\text { Increasing recognition by } \\
\text { government and other } \\
\text { specialists }\end{array}$ & $\begin{array}{l}\text { Not enough doctors } \\
\text { means volumes of } \\
\text { patients are high } \\
\text { Transactional vs } \\
\text { relationship mode } \\
\text { Comodification of health } \\
\text { Compliance with } \\
\text { medicine } \\
\text { Easy access to } \\
\text { diagnostics }\end{array}$ \\
\hline
\end{tabular}




\section{METHODS AND RESULTS}

Ethics committee approval was received from the Institute of Education, University College London and also from the Board of Governors of Nationwide, Bangalore. Data was gathered in English through a focus group and interviews with 11 family doctors and from video tapes of 18 consultations amounting to four and a half hours of doctor-patient time. The family physicians and patient both gave written informed consent. The time since qualification for the doctors ranged from three to thirty years. Four out of the eleven were female and five had worked in the UK. The transcribed data were analysed according to the stages of the inductive thematic analysis model described by [21]

From the interview and focus group data, five themes were created and are presented in Table 3.

Lack of space prevents a full discussion of these themes but some of the key points are highlighted here.

\section{THEME ONE}

\section{Medicine Reflects Societal Norms:}

Respondents felt that doctors occupy a place in Indian society that sets them on a pedestal, supported by both patients' and doctors' expectations. The doctor was presented by some participants as being expected, and expecting of themselves, to know the 'answer' to a patient's concerns. This is connected to the variation in educational opportunities across Indian society and, particularly in rural areas, where fewer than half of all patients might have gone beyond primary education.
Secondly, several doctors spoke of the need to consider the patient as one element of the family unit. The duty of confidentiality in UK general practice flows from the concept of autonomy; that an individual with capacity has usually sole control of information about himself. One approach to the delivery of a diagnosis, via a family member, is a feature of the general practice consultation that is very different from UK practice. A further feature is the social reticence about discussing sexual health matters and a taboo that still exists around mental health. In such circumstances, there seems to be a risk of a training deficit in enabling doctors to professionally and empathetically deal with such sensitive topics, and learn appropriate skills to manage patients.

\section{THEME TWO}

Language is more than Just Words - But They Help:

The ability to 'connect' with a patient was identified by several of these doctors as being a crucial feature of the family medicine consultation. It was perceived as a pre-requisite for empathy and a function of good communication skills, but depended on finding a common language between patient and doctor. Sometimes this was about eliciting symptoms and sometimes it was about giving instructions. Doctors felt that building empathy or 'connectedness' took time, a luxury they did not have. The additional challenge of learning a technical discipline like medicine in English, then needing to translate into language the patient could understand, was identified.

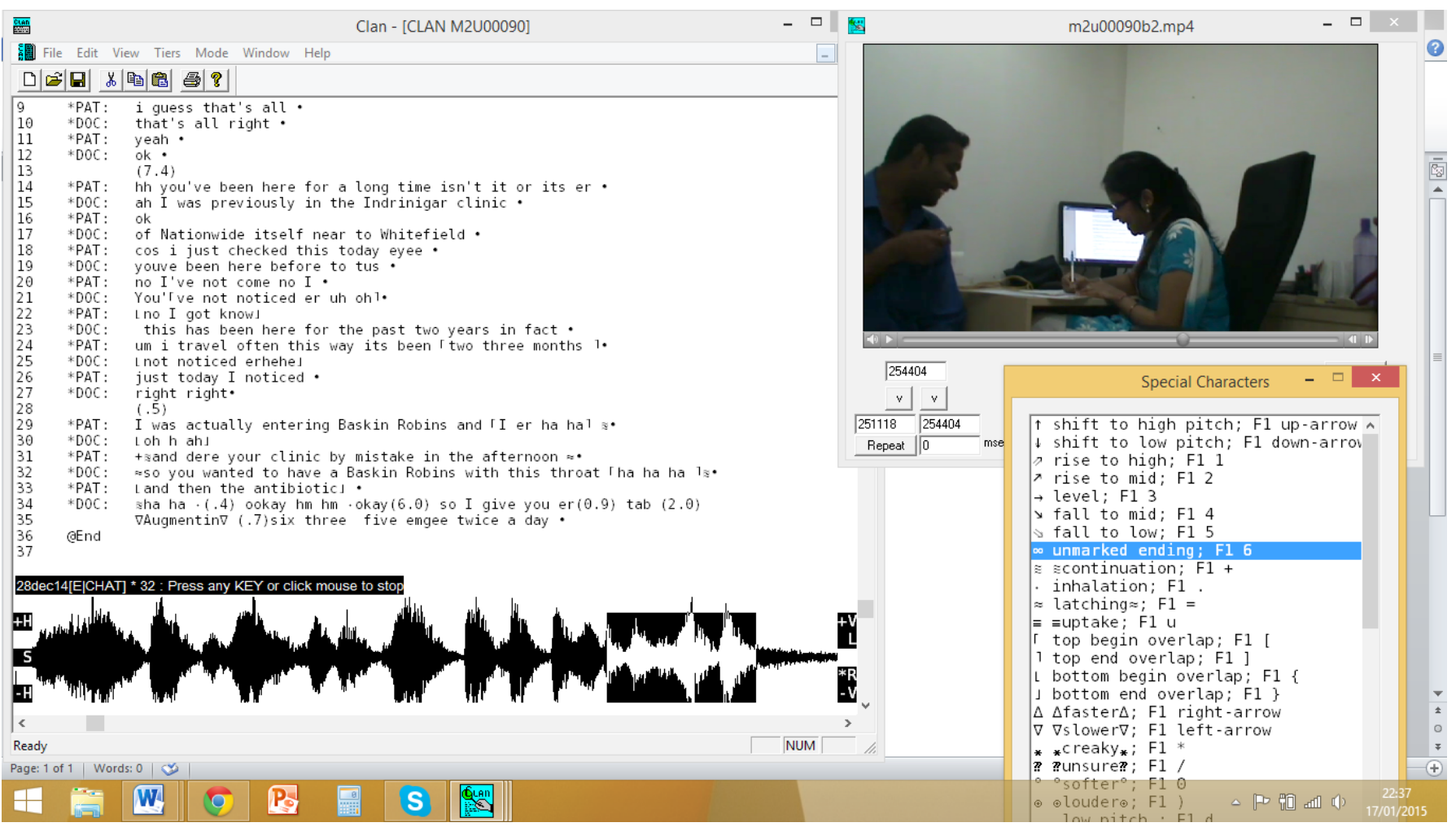

Fig. (1): Screenshot of CLAN in use. 


\section{THEME THREE}

Education and Training does not Prepare Us to Do the Job: Several of the doctors commented that they had no training, or even discussion, in how to talk to patients. They have identified a gap between the language of medicine as science, and medicine as it is practiced. Without explicit reference during training and education to communication skills as a technical skill set, it is likely to be harder to study and perfect the consultation, or to have either the vocabulary or set of constructs to note, respond to or modify interactional difficulties. A further aspect of concern relating to training was the absence of sufficient postgraduate training for general practice which was identified as a key barrier to raising both the standards in the practice of family medicine and the status of those taking it up.

\section{THEME FOUR}

Recognition of Family Medicine and General Practice:

Some of the doctors stated that the medical fraternity tends to look down on family physicians, which they linked to the lack of protection for the role through a licencing qualification. They were also seen to present competition for the private practice of secondary care specialists. In addition the role of the GP is also not well understood by patients who also seek reassurance from the expertise of secondary care specialists.

\section{THEME FIVE}

\section{The Influence of Money:}

Low investment in healthcare by federal and state governments translates into low numbers of doctors. There is one government doctor per 11,528 of the population in India. Even taking all registered doctors, which includes those abroad, those in private practice and those not working at all, data from the World Health Organization's Global Health Workforce Statistics shows there are only $0.7 \%$ per 1000 head of population in India compared to 2.8 in the UK [22].

Over $70 \%$ of all healthcare costs are borne out of pocket in India, which can bring about catastrophic, impoverishing outlay and lack of concordance with preventative or ongoing care.

\section{A FOCUS ON TALK IN INTERACTION}

The 18 video-recorded consultations were analysed with CLAN software (See Fig. 1) using a modified form of the Jefferson Transcription System [23].

Forms of talk can be considered along a spectrum proposed by Holmes that extends from 'core business work' through 'work-related' to 'social talk' and 'phatic communion', the last two of which she groups together as 'small talk' [19]. Small talk has been referred to as 'timeout' [24], and is sometimes considered 'minor, informal, unimportant and non-serious' [18] or 'conversation for its own sake'. Indeed, the doctors in the Nationwide clinic did not think they used small talk, one said: 'we don't talk about the weather'. This is supported by a suggestion in the literature that small talk is rare in multi-lingual settings, perhaps since it might lead to misunderstandings between doctors and patients or 'de-doctor' the professional in some situations. Holmes however makes a distinction between social talk, likely to be topicalized and relational, and phatic talk which although also pro-social contains no content. We have seen that 'conversationalising', is key to success in the CSA and it is possible that 'small talk' is seen by examiners as an important component of successful consulting. This was the analytical frame within which the video-tapes were reviewed.

The conversation analysis demonstrated many displays of medical knowledge using work talk that established the doctor in the role of knower. This is congruent with one theme expressed by the doctors in the thematic analysis that patients expect doctors to "know the answers'. In addition many examples of work-related talk were also noted, this is talk that could be described as 'the relational in the service of the institutional' where initially non-medical remarks uncovered other information through which the doctor achieved a new level of understanding about her patient.

In the four and a half hours of recorded data, there were also seventeen instances of social talk. This included talk which worked to 'fend off silence' including through pro-social back-channelling such as the nonlexical 'uh-huh' and short phrases such as 'I see'. The smallest of non-lexical utterances by a doctor can have an important interactional role in the production of medically relevant talk. Small talk was also seen in the data to enable 'dis attending' [24] for example during blood pressure monitoring, and to facilitate transition between activities. It worked to perpetuate cultural stories, and to create space then available for more medical work. In this data set, in contradistinction to the emphasis on 'conversationalising' in successful CSA consultations, when analysed interactionally there are very few examples of overt social talk. Despite this, however, relationships were formed and medical work was successfully done.

The data also includes one example where a small section of pro-social talk ends in silence. Small talk can create a'closeness' between doctor and patient, which might be uncomfortable and is perhaps considered inappropriate in this setting. In the thematic analysis we saw the discussion that the doctor-patient relationship reflected societal norms which, in a conservative society, includes maintaining a social distance. There thus seems to be a risk associated with small talk. This might explain why some re-located practitioners, like doctors from India coming to the UK, especially perhaps those working in a second language, less certain of their social position or unfamiliar with a shared vernacular, might avoid it. 


\section{CONCLUSION}

Competence with small talk or 'conversationalising' is important for success in the CSA but this research shows that the nature of socially appropriate talk can be very variable from one context to another. The differential success rate for different subgroups of doctors from cultures with naturally different mode of consulting might be one of the unintended consequences of focusing on interactional fluidity in assessment.

Doctors entering the UK from India will bring with them an understanding of the doctor-patient relationship which has been shaped by their own experiences as citizens, patients, students and practitioners. They will project themselves as the good doctor using cues that will have been largely 'caught not taught' socially in the way that Bourdieu describes the unheeded acquisition of invisible capital that gives a sense of 'position' within a social setting' [25].

In addition the current under-theorised role talk itself plays in successful consulting seems likely to be one of the factors that underpins the current differential success rates for international medical graduates in the RCGP assessment of consulting skills. As Goodwin (1991) points out:

Conversing...cannot simply be seen as a problem of putting information into words or, for that matter, of using the right grammar or choosing appropriate expressions. It is a collaborative enterprise involving the coordinated efforts of speakers and listeners in the production of interactional outcomes [12].

Goodwin (1991) quoted by Gumpertz in Drew and Heritage (1992, p305).

Overseas-trained doctors coming to the NHS are required to pass an English language test, but there is not a direct link between knowledge of a language and ability to consult effectively. The need to connect efficiently with a patient, to step up to the challenge faced in taking a sexual or psychiatric history, or the need to connect quickly with a patient to facilitate the patient in explaining their symptoms and concerns in a time pressured consultation suggest a role for language that goes beyond the technical, scientific basis of medicine. But our methods for assessing competence with that are imperfect. The analysis of this data suggests that effective consulting can be achieved via a wide range of interactional patterns, some of which might not be easily recognised by CSA examiners steeped in the invisible norms of their own culture.

Until or unless the RCGP changes its assessment strategy, one recommendation that could reasonably be made for those preparing for the CSA is that candidates should make the most of the full range of talk available to them to demonstrate the sort of interactional fluidity that helps an examiner have confidence in the candidate, including small talk. However any advice of the 'do it like this' variety arising from this project and aiming to support IMGs in the CSA, risks reinforcing the perception of a 'deficit' model of consulting for those trained outside the UK. Given that one of the criticisms from RCGP examiners is that poorly performing candidates sound formulaic or lack fluency, it would seem to be counter-productive to offer candidates another model of 'good consulting' to emulate. For both these reasons this paper does not seek to offer such a 'check-list' approach. Conversation analysis relies on an understanding that the work done by talk is displayed in how the hearer responds to it but that meaning is co-constructed between the speaker and the hearer as they work collaboratively 'in the moment'. Candidates who listen and respond to the patient in front of them, following the lead of the patient and attending carefully to what is said, will do better in the CSA than those trying to follow a pre-defined scheme of consulting. This advice applies to all trainees, wherever trained, who are endeavouring to demonstrate that they can consult effectively and efficiently with patients. It is likely to make them better doctors too.

\section{CONFLICT OF INTEREST}

The author declares no conflict of interest.

\section{ACKNOWLEDGEMENTS}

I am grateful to have received funding in the form of a Travel Fellowship from the Association for the Study of Medical Education in Europe and from Keele University School of Medicine. Doctors and patients in the Nationwide Clinic, Bangalore generously opened up a window into their private consulting spaces, without which this work would have been impossible. Thank you.

\section{DISCLOSURE}

Part of this article has previously been published in the thesis entitled "A description of some of the features of general practice consultations in a clinic in India with reference to the Clinical Skills Assessment (CSA) of the United Kingdom Royal College of General Practitioners" available at https://discovery.ucl.ac.uk/id/ eprint/1538682/.

\section{REFERENCES}

1. Differential attainment. General Medical Council, 2019. Available at: https://www.gmc-uk.org/education/standards-guidance-andcurricula/projects/differential-attainment [Accessed on: 5.8.19].

2. Royal College of General Practitioners. MRCGP Statistics 201718: Annual Report on the AKT and CSA Assessments. 2018. Available from: https://www.rcgp.org.uk/-/media/Files/GP-trainingand-exams/Annual-reports/MRCGP-annual-report-aug-2017jul-2018.ashx?la=en.

3. Pati S, Sharma A, Pati S, Zodpey S. Family medicine education in India: a panoramic view. J Family Med Prim Care 2015; 4(4): 495.

4. Indian Government Planning Commission. Twelfth, five year plan (2012-17). New Delhi, India: 2013. Available at: http:// planningcommission.gov.in/plans/planrel/12thplan/pdf/12fyp vol3. pdf [Accessed on: 05.5.19].

5. Roberts $\mathrm{C}$, Atkins $\mathrm{S}$, Hawthorne K. Performance features in clinical skills assessment: linguistic and cultural factors in the membership 
of the Royal College of General Practitioners examination. London: Centre for Language, Discourse \& Communication, King's College London 2014.

6. Moore $M$. What does patient-centred communication mean in Nepal? Med Educ 2008; 42(1): 18-26.

7. Claramita M, Susilo AP, Kharismayekti M, van Dalen J, van der Vleuten C. Introducing a partnership doctor-patient communication guide for teachers in the culturally hierarchical context of Indonesia. Educ Health 2013; 26(3): 147.

8. Claramita M, Nugraheni MD, van Dalen J, van der Vleuten C. Doctor-patient communication in Southeast Asia: a different culture? Adv Health Sci Educ 2013; 18(1): 15-31.

9. Claramita M, Utarini A, Soebono H, Van Dalen J, Van der Vleuten C. Doctor-patient communication in a Southeast Asian setting: The conflict between ideal and reality. Adv Health Sci Educ 2011; 16(1): 69-80.

10. Claramita M, Van Dalen J, Van Der Vleuten CP. Doctors in a Southeast Asian country communicate sub-optimally regardless of patients' educational background. Patient Educ Couns 2011; 85(3): e169-e74.

11. Cameron D. Working with spoken discourse. $1^{\text {st }}$ ed. Oxford: Sage 2001.

12. Drew P, Heritage J. Talk at work. Interaction in institutional settings. Cambridge: Cambridge University Press 1993.

13. Sidnell J. Conversation Analysis. Chichester: Wiley-Blackwell 2010.

14. Malinowski $B$. The problem of meaning in primitive languages. In: Ogden CK, Richards IA, Eds. The meaning of meaning: a study of the influence of language upon thought and of the science of symbolism. New York: Harcourt, Brace \& World, Inc. 1923, 296336.
15. Laver J. Communicative functions of phatic communion. In: Kendon A, Harris RM, Key MR, Eds. Organization of behavior in face-to-face interaction. The Hague: Mouton 1975.

16. Brown P, Levinson SC, Levinson SC. Politeness: some universals in language usage. Cambridge: Cambridge University Press 1987.

17. Spencer-Oatey H. Face, (im) politeness and rapport. In: SpencerOatey H. Face, Ed. Culturally speaking: culture, communication and politeness theory. London: Continuum International Publishing Group 2008.

18. Coupland J. Introduction: sociolinguistic perspectives on small talk. Small talk. New York: Pearson Education Limited 2000, 1-25.

19. Holmes, J. Doing collegiality and keeping control at work. In: Coupland J, Ed. Small talk. New York: Pearson Education Limited 2000.

20. Mak BCN, Chui HL. A cultural approach to small talk: a doubleedged sword of sociocultural reality during socialization into the workplace. J Multicult Discourses 2013; 8(2): 118-33.

21. Braun V, Clarke V. Using thematic analysis in psychology. Qual Res Psychol 2006; 3(2): 77-101.

22. Bank TW. World Health Organization's Global Health Workforce Statistics, OECD, supplemented by country data. Available from: https://data.worldbank.org/indicator/sh.med.phys.zs.

23. Atkinson J HJ. Structures of social action, studies in conversation analysis. Cambridge: Cambridge University Press 1984.

24. Maynard DW, Hudak PL. Small talk, high stakes: interactional disattentiveness in the context of prosocial doctor-patient interaction. Lang Soci 2008; 37(5): 661-88.

25. Bourdieu P. Social space and symbolic power. Sociol Theory 1989; $7(1): 14-25$. 